
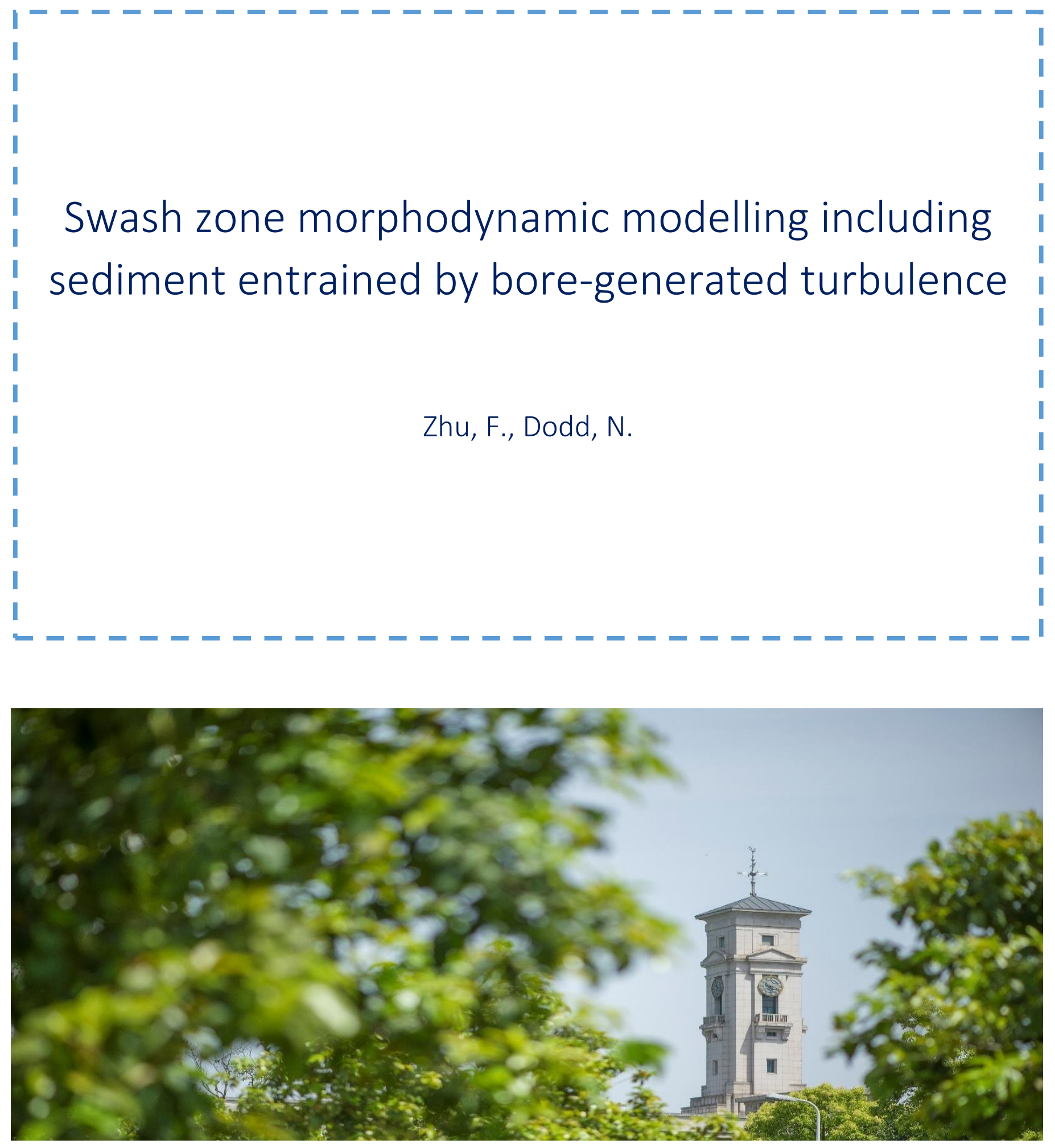
University of Nottingham Ningbo China, 199 Taikang East Road, Ningbo, 315100, Zhejiang, China.

First published 2020

This work is made available under the terms of the Creative Commons Attribution 4.0 International License:

http://creativecommons.org/licenses/by/4.0

The work is licenced to the University of Nottingham Ningbo China under the Global University Publication Licence:

https://www.nottingham.edu.cn/en/library/documents/researchsupport/global-university-publications-licence-2.0.pdf 


\title{
Swash zone morphodynamic modelling including sediment entrained by bore-generated turbulence
}

\author{
Fangfang Zhu ${ }^{\mathrm{a}, *}$, Nicholas Dodd ${ }^{\mathrm{b}}$ \\ ${ }^{a}$ Department of Civil Engineering, University of Nottingham, Taikang East Road, Ningbo, \\ 315100, China \\ ${ }^{b}$ Faculty of Engineering, University of Nottingham, Nottingham NG7 2RD, UK
}

\begin{abstract}
In this paper we introduce a mathematical model of sediment entrainment due to bore-generated turbulence in a shallow water context. In this model, the entrainment is assumed to be proportional to the energy decay rate across a bore on a mobile bed. The energy decay rate across a bore on a mobile bed is derived analytically. This model is incorporated into the one dimensional morphodynamic model developed by [1], which includes bed- and suspended load transport. This results in new shock conditions, which allow for sediment entrainment at a shock. With it we investigate the effects of sediment entrainment due to bore-generated turbulence on beachface evolution under a single swash event driven by a solitary wave. The simulation results imply that sediment entrainment by bore turbulence at the incoming bore dominates over sediment mobilisation by bed shear stress. In contrast, the backwash bore is dominated by bed shear stress related processes. The morphodynamic impact of bore turbulence on this swash event is primarily erosion of the sea bed seaward of the initial shoreline. Any sediment remaining in the water column seaward of this point is then available to be transported by subsequent events. It is shown that the bed step is primarily a bed load related feature, with sediment entrained as suspended load counteracting the bed step growth.
\end{abstract}

Keywords: swash, bore turbulence, sediment entrainment, beach change

\footnotetext{
${ }^{*}$ Corresponding author

URL: Fangfang.zhu@nottingham.edu.cn (Fangfang Zhu)
}

Preprint submitted to Advances in Water Resources

August 3, 2020 


\section{Introduction}

The swash zone is a very dynamic region in which the beachface is repeatedly submerged and dried, and in which considerable sediment is transported, as both bed and suspended load. In the nearshore, waves often break, forming

5 incoming bores that propagate through the inner surf zone, sometimes collapsing on steeper beaches, and resulting in swash motions 2, 3, 4.

Bore turbulence has been recognised as being important for sediment suspension [4, 5, 6, 3, 7. Both field and laboratory measurements show that high suspended sediment concentrations (hereinafter SSC) are found associated with the passing of bore fronts $[3,8$.

Sediment suspended by bore turbulence has been included in some modelling approaches [5, 7], typically using the Nonlinear Shallow Water Equations (NSWEs), in which bores can be naturally simulated as shocks [9]. In the NSWE-based cross-shore suspended sediment transport model developed by [ $[$, the sediment suspension term was related to energy dissipation due to both bottom friction and wave breaking. The total energy dissipation at each position is calculated from the numerically solved water depth and depth-averaged velocity via the energy conservation equation. The energy dissipation due to wave breaking is further separated from that due to bed friction. The suspension and settling of sediment are then linked to a bed change equation to allow morphological change. [7] extend the approach of [5] by considering a transport equation for turbulence, and by considering the vertical distribution of suspended sediment.

These approaches have proved valuable, and indeed that of [7] suggests the importance of bore turbulence in transporting sediment onshore. In both studies energy dissipation, which is linked to the turbulence generation, which in turn entrains sediment, is back-calculated from the energy equation. However, there is a well-known analytical expression for energy loss rate at a hydrodynamic bore 
on a fixed bed under the framework of the NSWEs [10, p. 291-341]. In principle this should yield the same energy loss (due to bore-generated turbulence alone) as that from the energy equation [5, 7. However, the latter approach relies in principle on evaluating gradients across bore faces, which, in theory, possess infinite gradients, whereas the analytical expression only involves quantities either side of the bore. This analytical expression was employed in a related context by [11, although driven by laboratory measurements.

This motivates our study. We seek to derive an analytical expression for energy dissipation at a shock on a mobile bed, and to use this expression directly to estimate sediment entrainment at a bore. In doing so we make use of the Specified Time Interval Method of Characteristics (STI MOC) numerical scheme 40 together with shock fitting method adopted by [1]; this is attractive because the shock is tracked, and therefore conditions either side of it known to a high degree of accuracy. In order to incorporate the new energy dissipation expression within an NSWE system we utilise a Dirac delta function in the source terms of the equations for suspended load and bed change, and this in turn leads to new shock conditions.

In order to investigate the effect of sediment entrainment by bore turbulence, we examine a swash event driven by a solitary wave in which an incoming bore (shock) forms when the solitary wave approaches a sloping beach and a backwash bore forms when the flow recedes. We focus on the influence of bore turbulence on the depth-averaged SSC and swash zone bed evolution.

In $\S 2$ we present the model equations. We also examine the new shock conditions, and develop an expression representing the sediment entrainment at a bore. We then in $\S 3$ develop the analytical expression for energy dissipation at a bore on a mobile bed. In $\S 4$ we simulate the solitary wave swash event considered by [12, 1], to examine the effect that this has on the morphodynamics of such an event. In $\S 5$, we discuss the uncertainty of our approximation of some parameters. In $\S 6$, we draw conclusions. 


\section{Model development}

\subsection{Governing equations}

The NSWEs including bed shear stress are utilised to describe the flow. The bed level and the depth-averaged SSC changes are governed by the Exner equation and suspended sediment advection equation, in which bed and suspended loads due to bed shear stress as well as sediment suspended by bore-generated turbulence are included. Therefore, the governing equations are:

$$
\begin{aligned}
\hat{h}_{\hat{t}}+\hat{u} \hat{h}_{\hat{x}}+\hat{h} \hat{u}_{\hat{x}} & =0 \\
\hat{u}_{\hat{t}}+\hat{u} \hat{u}_{\hat{x}}+g \hat{h}_{\hat{x}}+g \hat{B}_{\hat{x}} & =-\frac{c_{d}|\hat{u}| \hat{u}}{\hat{h}} \\
\hat{B}_{\hat{t}}+\xi \hat{q}_{\hat{x}} & =\xi(\hat{D}-\hat{E})-\xi \hat{\mathcal{G}}(\hat{x}) \delta(\hat{x}-\hat{\zeta}), \\
(\hat{h} \hat{c})_{\hat{t}}+(\hat{h} \hat{u} \hat{c})_{\hat{x}} & =(\hat{E}-\hat{D})+\hat{\mathcal{G}}(\hat{x}) \delta(\hat{x}-\hat{\zeta}),
\end{aligned}
$$

${ }_{65}$ where $\hat{x}$ represents cross-shore distance $(\mathrm{m}), \hat{t}$ is time $(\mathrm{s}), \hat{h}$ represents water depth $(\mathrm{m}), \hat{u}$ is a depth-averaged horizontal velocity $\left(\mathrm{ms}^{-1}\right), \hat{B}$ is the bed level $(\mathrm{m}), \hat{c}$ is the depth-averaged $\mathrm{SSC}\left(\mathrm{m}^{3} / \mathrm{m}^{3}\right), c_{d}$ is a dimensionless drag coefficient, $\hat{q}$ is sediment flux due to bed load $\left(\mathrm{m}^{2} \mathrm{~s}^{-1}\right), \hat{E}$ is the dimensional erosion (or entrainment) rate $\left(\mathrm{ms}^{-1}\right)$ due to bed shear stress, and $\hat{D}$ is the dimensional deposition rate $\left(\mathrm{ms}^{-1}\right)$ (regardless of what entrained the sediment in the first place). Here, $\xi=\frac{1}{1-p}$ with $p$ being bed porosity, and $g$ is acceleration due to gravity $\left(\mathrm{ms}^{-2}\right) . \hat{\mathcal{G}}(\hat{\mathcal{G}} \geq 0)$ represents the entrainment rate of sediment at a shock due to bore turbulence $\left(\mathrm{ms}^{-1}\right) . \quad \delta$ is the dimensionless Dirac Delta function, and $\hat{\zeta}$ is shock position $(\mathrm{m})$. The sediment entrainment due to bore

75 turbulence is multiplied by a Dirac delta function to ensure a non-zero value for sediment entrainment from (3) and (4) via the shock conditions (see $\S 2.3$ ).

We use the following forms for $\hat{q}, \hat{E}$ and $\hat{D}[1$ :

$$
\hat{q}=\hat{A}\left(\frac{\hat{u}^{2}}{\hat{u}_{0}^{2}}\right)^{3 / 2} \frac{|\hat{u}|}{\hat{u}}, \quad \hat{E}=\hat{m}_{e} \frac{\hat{u}^{2}}{\hat{u}_{0}^{2}}, \quad \hat{D}=\hat{w}_{s} \hat{c}
$$

where $\hat{A}$ is dimensional bed-load sediment transport rate $\left(\mathrm{m}^{2} \mathrm{~s}^{-1}\right), \hat{m}_{e}$ is the parameter describing the erodibility of the bed $\left(\mathrm{ms}^{-1}\right)$ as suspended load due 
to bed shear stress, $\hat{w}_{s}$ is the effective settling velocity of suspended sediment $\left(\mathrm{ms}^{-1}\right)$, and $\hat{u}_{0}$ is a representative velocity scale (used here so that $\hat{A}$ has the dimensions of $\hat{q}$ ). We choose this form for $\hat{q}$ because it is a form to which many bed-load formulae [13] reduce if a threshold of motion $\left(\hat{u}_{c r}\right)$ is ignored, namely $\hat{q} \propto \hat{u}^{3}$. The choice $\hat{u}_{c r}=0$ is generally reasonable in the swash [1], and desirable

${ }_{85}$ here because we wish to examine the morphodynamics so we can understand the various roles played by processes.

In this work, as mentioned, we also [5, 7] make an assumption that $\hat{\mathcal{G}}$ is proportional to the energy loss rate across a shock, which itself is assumed to be proportional to the rate of sediment entrainment by bore turbulence. This means that we do not consider explicit turbulence modelling here. We consider the consequences of this in the Discussion section.

Further, it seems reasonable to assume that $\hat{\mathcal{G}} \propto \hat{m}_{e}$ (see $\sqrt{5}$ ), because $\hat{\mathcal{G}}$ is a measure of the erodibility of the same sand, but due to bore-generated turbulence rather than bed shear stress. However, we also aim to examine entrainment

95 by bore turbulence independent from entrainment by bed shear stress, so we introduce $\hat{m}_{b}$, which serves the same purpose as $\hat{m}_{e}$, but for sediment entrained as suspended load by bore turbulence. Here it is convenient to set $\hat{m}_{b}=\hat{m}_{e}$, unless we wish to examine sediment entrainment by bore turbulence only, in which case we set $\hat{m}_{e}=0$ only. Therefore, at the bore location we take

$$
\hat{\mathcal{G}}=\hat{m}_{b} \hat{k} \frac{1}{\rho g} \frac{d \hat{\mathcal{E}}}{d \hat{t}}=\hat{m}_{b} \hat{\mathcal{G}}^{\prime}
$$

100 where $\frac{d \hat{\mathcal{E}}}{d t}$ is energy loss rate per unit width $\left(\mathrm{kgms}^{-3}\right)$, where $\frac{d \hat{\mathcal{E}}}{d t}>0$, and $\hat{k}$ is a dimensional parameter $\left(\mathrm{m}^{-3} \mathrm{~s}\right)$. In Appendix A we discuss why our choice for $\hat{\mathcal{G}}$ differs from that of [5].

Therefore, (3) and (4) become:

$$
\begin{aligned}
\hat{B}_{\hat{t}}+3 \xi \frac{\hat{A}}{\hat{u}_{0}^{3}} \hat{u}^{2} \hat{u}_{\hat{x}} & =\xi\left(\hat{w}_{s} \hat{c}-\hat{m}_{e} \frac{\hat{u}^{2}}{\hat{u}_{0}^{2}}\right)-\xi \hat{m}_{b} \hat{\mathcal{G}}^{\prime}(\hat{x}) \delta(\hat{x}-\hat{\zeta}), \\
(\hat{h} \hat{c})_{\hat{t}}+(\hat{h} \hat{u} \hat{c})_{\hat{x}} & =\left(\hat{m}_{e} \frac{\hat{u}^{2}}{\hat{u}_{0}^{2}}-\hat{w}_{s} \hat{c}\right)+\hat{m}_{b} \hat{\mathcal{G}}^{\prime}(\hat{x}) \delta(\hat{x}-\hat{\zeta}) .
\end{aligned}
$$




\subsection{Non-dimensionalization}

105 are:

$$
x=\frac{\hat{x}}{\hat{h}_{0}}, t=\frac{\hat{t}}{\hat{h}_{0}^{1 / 2} g^{-1 / 2}}, h=\frac{\hat{h}}{\hat{h}_{0}}, u=\frac{\hat{u}}{\hat{u}_{0}}, B=\frac{\hat{B}}{\hat{h}_{0}}, c=\frac{\hat{c}}{\hat{c}_{0}} \text { and } \mathcal{E}=\frac{\hat{\mathcal{E}}}{\rho g \hat{h}_{0}^{3}}
$$

where $\hat{h}_{0}$ is a length scale, $\hat{c}_{0}=\frac{\hat{m}_{e}}{\hat{w}_{s}}$ is a reference concentration and $\hat{u}_{0}=$ $\left(g \hat{h}_{0}\right)^{1 / 2}$.

Using (9), (1) and 22) become

$$
\begin{aligned}
h_{t}+u h_{x}+h u_{x} & =0, \\
u_{t}+u u_{x}+h_{x}+B_{x} & =-\frac{c_{d}|u| u}{h} .
\end{aligned}
$$

Substituting (9) into (7) and (8) gives

$$
\begin{aligned}
B_{t}+3 \xi \frac{\hat{A}}{\hat{h}_{0}\left(g \hat{h}_{0}\right)^{1 / 2}} u^{2} u_{x}=\xi \frac{\hat{m}_{e}}{\left(g \hat{h}_{0}\right)^{1 / 2}}\left(c-u^{2}\right)-\frac{\xi \hat{m}_{b}}{\left(g \hat{h}_{0}\right)^{1 / 2}} \hat{k} g^{1 / 2} \hat{h}_{0}^{5 / 2} \frac{d \mathcal{E}}{d t} \delta(x-\zeta), \\
(h c)_{t}+(h u c)_{x}=\frac{\hat{w}_{s}}{\left(g \hat{h}_{0}\right)^{1 / 2}}\left(u^{2}-c\right)+\frac{\hat{w}_{s}}{\left(g \hat{h}_{0}\right)^{1 / 2}} \hat{k} g^{1 / 2} \hat{h}_{0}^{5 / 2} \frac{d \mathcal{E}}{d t} \delta(x-\zeta) .
\end{aligned}
$$

Letting

$\sigma=\xi \frac{\hat{A}}{\hat{h}_{0}\left(g \hat{h}_{0}\right)^{1 / 2}}, M=\xi \frac{\hat{m}_{e}}{\left(g \hat{h}_{0}\right)^{1 / 2}}, M_{b}=\xi \frac{\hat{m}_{b}}{\left(g \hat{h}_{0}\right)^{1 / 2}}, \epsilon=\frac{\hat{w}_{s}}{\left(g \hat{h}_{0}\right)^{1 / 2}}, k=\hat{k} g^{1 / 2} \hat{h}_{0}^{5 / 2}$, and with $M=M_{b}, 12$ and (13) are simplified to:

$$
\begin{aligned}
B_{t}+3 \sigma u^{2} u_{x} & =M\left(c-u^{2}\right)-M_{b} \mathcal{G}^{\prime}(x) \delta(x-\zeta), \\
(h c)_{t}+(h u c)_{x} & =\epsilon\left(u^{2}-c\right)+\epsilon \mathcal{G}^{\prime}(x) \delta(x-\zeta),
\end{aligned}
$$

where

$$
\mathcal{G}^{\prime}(x)=k \frac{d \mathcal{E}}{d t} .
$$

Considering bed load formulae in [13, p. 157-163], and taking $0.001<c_{d}<0.01$, then $0.0001<\sigma<0.02$. Here we choose $\sigma=0.01$ as a default value. $M$ is more difficult to estimate. From the field calibration of [1] a range $0.0002<M<$ 0.002 is reasonable. Here we take $M=0.001$ as a default value. Finally, $\epsilon \propto$ 
grain size; we take $\epsilon=0.01$ as a default, which, for $\hat{h}_{0}=1 \mathrm{~m}, \Rightarrow \hat{w}_{s} \approx 0.032$ $\mathrm{m} / \mathrm{s}$, and therefore grain size $\approx 0.27 \mathrm{~mm}$, corresponding to a medium sand [13].

The energy decay rate $\frac{d \mathcal{E}}{d t}$ across a morphodynamic shock is derived in $\S 3.1$ However, note that if $M=0$ and $M_{b} \neq 0$ (i.e., $\hat{m}_{e}=0$ and $\hat{m}_{b} \neq 0$ ), we set $\hat{c}_{0}=\frac{\hat{m}_{b}}{\hat{w}_{s}}$. The dimensionless governing equations then become

$$
\begin{aligned}
B_{t}+3 \sigma u^{2} u_{x} & =M_{b} c-M_{b} \mathcal{G}^{\prime}(x) \delta(x-\zeta), \\
(h c)_{t}+(h u c)_{x} & =-\epsilon c+\epsilon \mathcal{G}^{\prime}(x) \delta(x-\zeta) .
\end{aligned}
$$

See Appendix B for details of the non-dimensionalization for the case $M=0$ but $M_{b} \neq 0$. We use (17) and (18) in the investigation of the bore-turbulence-only case.

Equations 10, (11) and 14), 15) (or 17), 18) can be rewritten in characteristic form such that in characteristic directions

$$
\frac{d x}{d t}=\lambda_{i} \quad \text { for } \quad i=1-4
$$

we have 4 Riemann equations. $\lambda_{1}<\lambda_{3}<\lambda_{2}$, where $\lambda_{1}<0$ and $\lambda_{2}>0$, and $\lambda_{4}=u$ [see 1]. For subcritical flow and a slightly erodible bed $\lambda_{1,2}$ behave like the hydrodynamic characteristics, and $\lambda_{3}$ is the bed wave speed, although these identities can change for larger Froude numbers [1].

\subsection{Shock conditions}

Applying mass and momentum conservation across a shock, i.e., a bore, gives the conditions:

$$
\begin{aligned}
-W\left(h_{R}-h_{L}\right)+\left(h_{R} u_{R}-h_{L} u_{L}\right) & =0, \\
-W\left(h_{R} u_{R}-h_{L} u_{L}\right)+\left(h_{R} u_{R}^{2}+\frac{1}{2} h_{R}^{2}-h_{L} u_{L}^{2}-\frac{1}{2} h_{L}^{2}\right) & \\
+\frac{1}{2}\left(h_{R}+h_{L}\right)\left(B_{R}-B_{L}\right) & =0, \\
-W\left(B_{R}-B_{L}\right)+\sigma\left(u_{R}^{3}-u_{L}^{3}\right) & =-M_{b} G, \\
-W\left(h_{R} c_{R}-h_{L} c_{L}\right)+\left(h_{R} u_{R} c_{R}-h_{L} u_{L} c_{L}\right) & =\epsilon G,
\end{aligned}
$$

135

where the subscripts $L$ and $R$ represent the left and right sides of the bore. $W$ is the shock velocity, and $G=G(\zeta)=\int_{\zeta^{-}}^{\zeta^{+}} \mathcal{G}^{\prime}(x) \delta(x-\zeta) d x=k \frac{d \mathcal{E}}{d t}$ represents the 
sediment entrainment rate by bore-generated turbulence at the shock. To get 21, the [14] approximation, i.e., $\int_{B_{L}}^{B_{R}} h d B=\frac{1}{2}\left(h_{L}+h_{R}\right)\left(B_{R}-B_{L}\right)$, is applied. For derivation of shock conditions for mass and momentum conservation we refer to [10, p. 314-318] and [15], p. 34-46].

Rearranging Eq. (20) gives

$$
h_{L} v_{L}=h_{R} v_{R}=m_{s}
$$

where

$$
u_{L}-W=v_{L}, \quad u_{R}-W=v_{R},
$$

and $m_{s}$ represents the mass flux across the shock front.

Eq. (23) can be simplified using Eq. (24) to:

$$
m_{s}\left(c_{R}-c_{L}\right)=\epsilon G \text {. }
$$

145

\subsection{Discussion of flow behaviour at a bore}

Because $\epsilon G>0$ in Eq. (26), $m_{s}<0$ (e.g. a bore travelling from left to right into still water) $\Rightarrow c_{L}>c_{R}$ (and $m_{s}>0 \Rightarrow c_{L}<c_{R}$ ). And when $m_{s}<0$, $u_{L}<W$ (by (24) and (25) so the downstream side of the shock is the left side. Thus water particles move from right (upstream) to left, and $c_{L}>c_{R}$, because of the sediment entrainment at the bore. This can also be explained by looking at the characteristics. The $\lambda_{4}=u$ characteristic on the upstream side of the shock always moves into the shock as $t$ increases, and thus the concentration $c$ on the upstream side is determined by the Riemann equation from upstream, which is not affected by bore turbulence.

155 the shock overtakes the flow, and so there is an increase in the sediment concentration behind the shock. In contrast, $c$ is continuous across shocks if sediment is only entrained by bed shear stress 1 .

If, to simplify the discussion, it is assumed that bed load and suspended load entrained by bed shear stress are excluded, then sediment can only be entrained by bore turbulence, and then transported as suspended load, and 
deposited under gravity. Accordingly, if we set $\sigma=0$ and $M=0$, in the equation governing bed load by bed shear stress, the shock condition Eq. 22 becomes

$$
\begin{aligned}
-W\left(B_{R}-B_{L}\right) & =-M_{b} G, \\
\Rightarrow B_{R}-B_{L} & =\frac{M_{b}}{W} G .
\end{aligned}
$$

$$
-W\left(h_{R} u_{R}-h_{L} u_{L}\right)+\left(h_{R} u_{R}^{2}+\frac{h_{R}^{2}}{2}-h_{L} u_{L}^{2}-\frac{h_{L}^{2}}{2}\right)-F_{b e d}=0,
$$

with $F_{b e d}=-\frac{1}{2}\left(B_{R}-B_{L}\right)\left(h_{R}+h_{L}\right)$. 


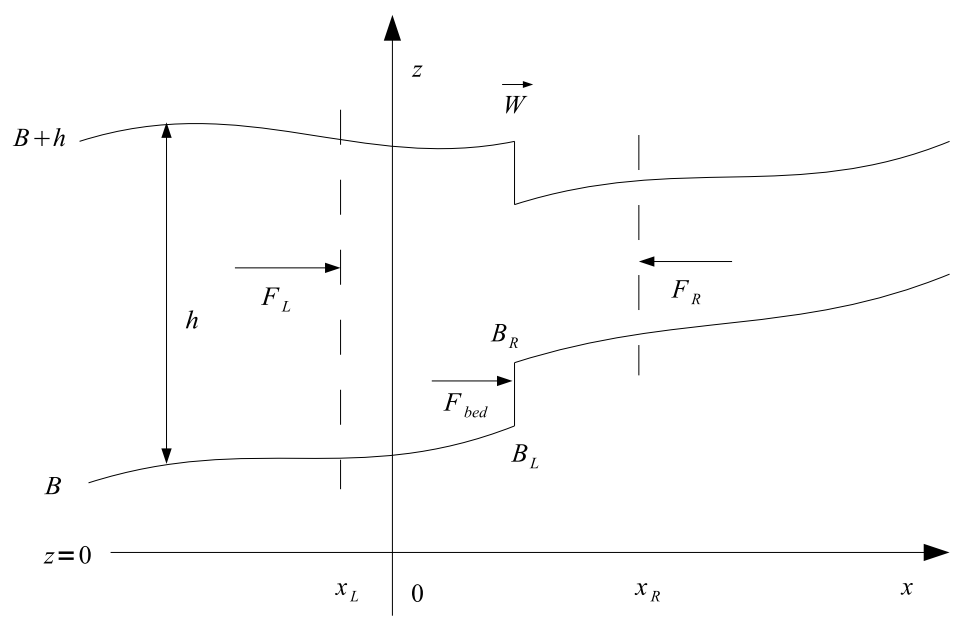

Figure 1: Schematic diagram of a morphodynamic shock. $F_{L}=h_{L}^{2} / 2$ and $F_{R}=h_{R}^{2} / 2$ are the hydrostatic pressure forces.

We consider the energy change in the domain $\left[x_{L}, x_{R}\right]$, with the shock position $x_{L}<\zeta<x_{R}$ (see Fig. 1). The water mass is conserved in the domain $\left[x_{L}, x_{R}\right]$, and $x_{L}$ and $x_{R}$ are moving at the speeds of the water particles, i,e., $\frac{d x_{L}}{d t}=u_{L}$ and $\frac{d x_{R}}{d t}=u_{R}$. The total energy, i.e., the sum of the kinetic and potential energies, in a volume $\mathcal{V}=\left[x_{L}, x_{R}\right] \times[B(x, t), B(x, t)+h(x, t)]$ of unit width is

$$
\begin{aligned}
E_{\text {in }} & =\int_{x_{L}}^{x_{R}} \int_{B}^{h+B}\left(z+\frac{1}{2} u^{2}\right) d z d x \\
& =\int_{x_{L}}^{x_{R}}\left(\frac{1}{2} h^{2}+B h+\frac{1}{2} h u^{2}\right) d x, \quad \text { as } x_{L} \rightarrow x_{R} .
\end{aligned}
$$

The rate of change of $E_{i n}$ depends on energy supply/loss rate at the boundaries of the shock volume $\mathcal{V}$, and energy decay rate at the shock itself. The energy change rate due to external forces is

$$
\begin{aligned}
\frac{d E_{e x}}{d t} & =F_{L} u_{L}-F_{R} u_{R}+F_{b e d} W \\
& =\frac{1}{2} h_{L}^{2} u_{L}-\frac{1}{2} h_{R}^{2} u_{R}+F_{b e d} W
\end{aligned}
$$

where $\frac{1}{2} h_{L}^{2} u_{L}\left(-\frac{1}{2} h_{R}^{2} u_{R}\right)$ represents the rate of work done by the pressure force 
$F_{L}=\frac{1}{2} h_{L}^{2}\left(F_{R}=-\frac{1}{2} h_{R}^{2}\right)$ on the left (right) side, and $F_{b e d} W$ represents the rate of work done by the force due to the bed step.

From energy conservation we get $\frac{d E_{i n}}{d t}=\frac{d E_{e x}}{d t}-\frac{d \mathcal{E}}{d t}$. So, the rate of energy loss is

$$
\begin{aligned}
\frac{d \mathcal{E}}{d t} & =-\frac{d E_{i n}}{d t}+\frac{d E_{e x}}{d t}=-\frac{d E_{i n}}{d t}-\left[\frac{1}{2} h^{2} u\right]_{L}^{R}+F_{b e d} W \\
& =-\left[\left(\frac{1}{2} h^{2}+B h+\frac{1}{2} h u^{2}\right)(u-W)\right]_{L}^{R}-\left[\frac{1}{2} h^{2} u\right]_{L}^{R}+F_{b e d} W
\end{aligned}
$$

where $[\cdot]_{L}^{R}=\cdot_{R}-\cdot_{L}$, and $\frac{d \mathcal{E}}{d t} \geq 0$. Note that $\frac{d}{d t} \int_{x_{L}}^{x_{R}} \cdot d x=\frac{d}{d t} \int_{x_{L}}^{\xi^{-}} \cdot d x+$ $\frac{d}{d t} \int_{\xi^{+}}^{x_{R}} \cdot d x=\cdot\left(W-u_{L}\right)+\cdot\left(u_{R}-W\right)$ in the limit of $x_{L} \rightarrow \xi^{-}$and $x_{R} \rightarrow \xi^{+}$. Substituting Eqs. (24) and (25) into (33) gives

$$
\begin{aligned}
\frac{d \mathcal{E}}{d t}= & \left(\frac{1}{2} h_{L}+B_{L}+\frac{1}{2} u_{L}^{2}\right) m_{s}-\left(\frac{1}{2} h_{R}+B_{R}+\frac{1}{2} u_{R}^{2}\right) m_{s} \\
& +\frac{1}{2} h_{L}^{2} u_{L}-\frac{1}{2} h_{R}^{2} u_{R}+F_{b e d} W .
\end{aligned}
$$

200 From Eq. (30)

$$
F_{\text {bed }}=m_{s}\left(u_{R}-u_{L}\right)+\frac{1}{2} h_{R}^{2}-\frac{1}{2} h_{L}^{2} .
$$

Substituting (35) into (34) gives

$$
\frac{d \mathcal{E}}{d t}=\frac{1}{2}\left(2 h_{L}+2 B_{L}-2 h_{R}-2 B_{R}+v_{L}^{2}-v_{R}^{2}\right) m_{s}
$$

and using Eq. 211, we get:

$$
\frac{d \mathcal{E}}{d t}=m_{s}\left(u_{L}-u_{R}\right)^{2} \frac{h_{R}-h_{L}}{2\left(h_{R}+h_{L}\right)} .
$$

The expression is an extension of the well-known expression for energy decay of [10] to a mobile bed. We note that [17] arrived at a similar expression via a different route, i.e., 2D vorticity generation by breaking waves, in which Stoker's expression emerges, augmented by a bed-step term. [17] neglects the momentum contribution due to the bed-step, hence the difference.

\subsection{Expression for $G$}

As previously mentioned, we relate $G$, the sediment entrainment rate at the shock due to bore-generated turbulence, to the energy loss rate $\frac{d \mathcal{E}}{d t}$ across a 
shock on a mobile bed, which we have just derived:

$$
G=k \frac{d \mathcal{E}}{d t}=k m_{s}\left(u_{L}-u_{R}\right)^{2} \frac{h_{R}-h_{L}}{2\left(h_{R}+h_{L}\right)},
$$

such that $G>0$ (in other words, we insist on an entropy-preserving shock). This leaves $k$ as the only unknown in the formulation. In Appendix C we discuss the case of a hydraulic jump on a mobile bed with regard to determining $k$, but do not make use of it because of its non-physicality. Instead, we determine $k$ from field data.

\subsection{Estimation of $k$ from field data}

We can estimate $k$ values from the field measurements of SSC across an incoming bore in Fig. 4 of 3 . Three incoming bores at $\hat{t} \approx 35,115,270 \mathrm{~s}$ are $W=\frac{h_{L} u_{L}-h_{R} u_{R}}{h_{L}-h_{R}}=1.03$ and $m_{s}=\frac{h_{L}\left(u_{L}-W\right)+h_{R}\left(u_{R}-W\right)}{2}=-0.48$.

According to 37 , $\frac{d \mathcal{E}}{d t}=7.96 \times 10^{-2}$. Then, from Eq. 26,

$$
\begin{aligned}
k & =\frac{m_{s}\left(c_{R}-c_{L}\right)}{\epsilon \frac{d \mathcal{E}}{d t}} \\
& =\frac{m_{s}\left(c_{R}-c_{L}\right) \frac{\hat{m}_{e}}{\hat{w}_{s}}}{\epsilon \frac{\hat{m}_{e}}{\hat{w}_{s}} \frac{d \mathcal{E}}{d t}} \\
& =\frac{m_{s}\left(c_{R}-c_{L}\right) \frac{\hat{m}_{e}}{\hat{w}_{s}}}{\frac{M_{b}}{\xi} \frac{d \mathcal{E}}{d t}}
\end{aligned}
$$




$$
\Rightarrow k M_{b}=\frac{m_{s}\left(c_{R}-c_{L}\right) \frac{\hat{m}_{e}}{\hat{w}_{s}} \xi}{\frac{d \mathcal{E}}{d t}}=0.13
$$

For the second and third bores we follow a similar procedure to obtain $k M_{b}=$ while for $x \geq 4$ the beach is of a uniform slope, $\tan \alpha=1 / 15$. Therefore, for $x \geq 4, h(x, 0)=1-(x-4) \tan \alpha$, and $B(x, 0)=(x-4) \tan \alpha$. The initial shoreline $x_{s}(t=0)=19$. 


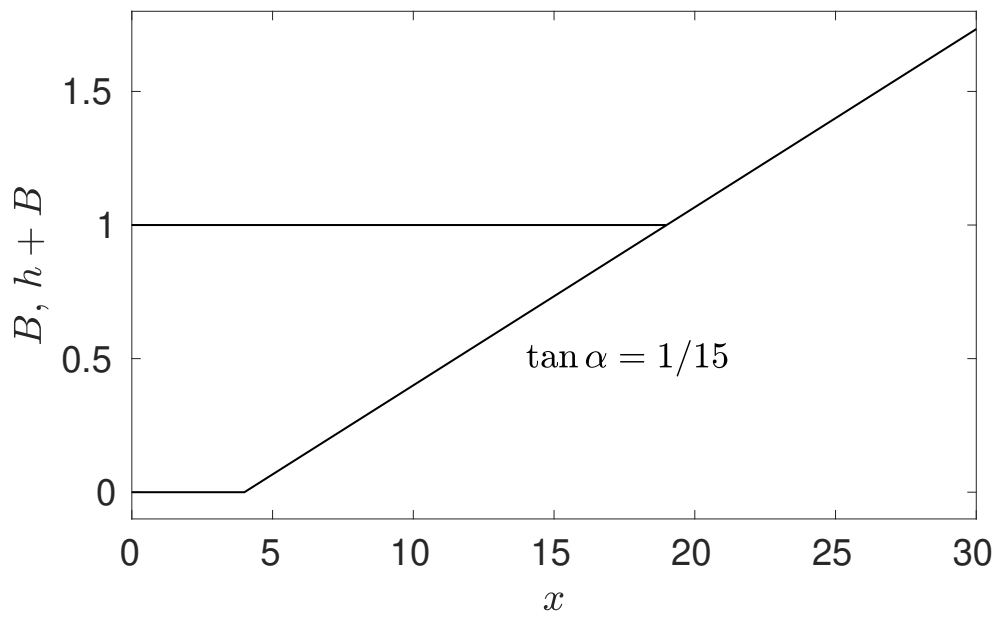

Figure 2: Initial conditions of the swash event driven from the seaward boundary $x=0$ over a first flat and then sloping beach.

A solitary wave is driven from the seaward boundary $(x=0)$, which is assumed to be absorbing / generating, such that dependent variables at the seaward boundary are approximated following the technique in [19].

Therefore, at the seaward boundary,

$$
\begin{aligned}
& \eta_{i}=H \operatorname{sech}^{2}\left(\left(\frac{3 H}{4}\right)^{1 / 2} \mathcal{C}_{0}(t-10)\right) \\
& u_{i}=2\left(\sqrt{h_{s}+\eta_{i}}-\sqrt{h_{s}}\right) \\
& u_{r}=-2\left(\sqrt{h_{s}+\eta_{r}(0, t)}-\sqrt{h_{s}}\right)
\end{aligned}
$$

where $H=0.6$ is wave height; $\mathcal{C}_{0}=\sqrt{1+H} ; h_{s}=1-B(0, t)$ is the still water depth at the seaward boundary allowing for bed change; $\eta_{i}\left(\eta_{r}\right)$ is the incident (reflected) wave free surface elevation (relative to still water surface), such that $h(0, t)=h_{s}+\eta_{i}+\eta_{r}$; and $u(0, t)=u_{i}(0, t)+u_{r}(0, t)$, where $u_{i}$ and $u_{r}$ are corresponding velocities associated with incident and reflected waves. Note that in Eqs. (40) and (41) we use the finite amplitude expressions for total water depth (rather than those from linear theory); the fact that incident and reflected waves do not co-exist much means that the loss of the principle of linear superposition is not significant, whereas the full free surface elevation is 
more accurately realised.

\subsection{Simulation results for suspended load due to bore turbulence only}

Here we set $\sigma=0, M=0, M_{b}=0.001$ (from [1]), and $\epsilon=0.01$, so that sediment can only be entrained by bore turbulence. The default value $k M_{b}=0.15$ gives $k=150$.

\subsubsection{Bore behaviour}

During the onshore propagation, an incoming $\left(\lambda_{2}\right)$ bore forms initially at $x \approx 0.08$ (see Fig. 3 ). Its strength starts to grow significantly at $(x, t) \approx(4,11)$ as it approaches the shore (see Fig. $4(\mathrm{~b}))$. A $\left(\lambda_{3}\right)$ bore also develops at $(x, t) \approx$ $(17,44)$ in the backwash. This backwash bore gradually slows down as it moves seawards, and its velocity approaches 0 at $(x, t) \approx(16.5,56)$.

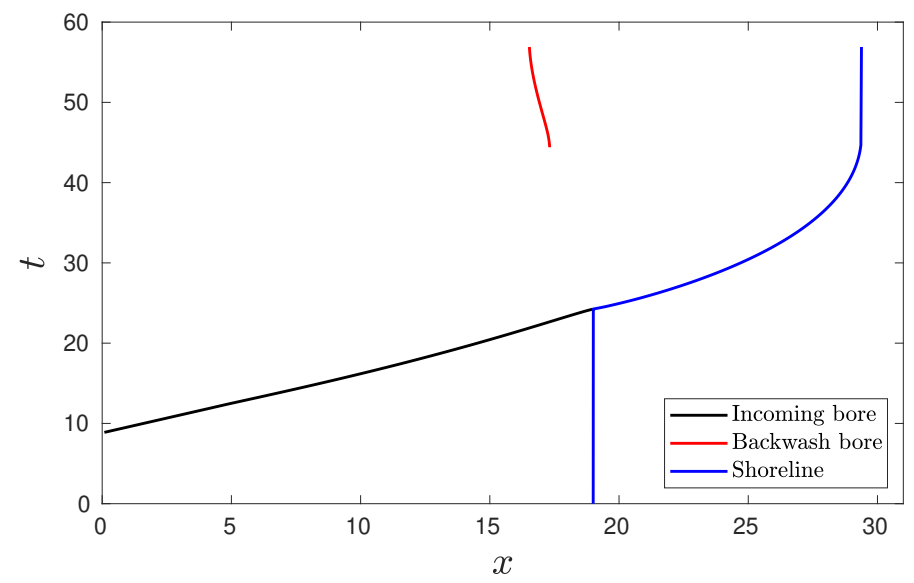

Figure 3: Shock paths of the incoming and backwash bores and also the shoreline. Note that consistent with the analysis of [20, 21] the instantaneous shoreline, $x_{s}(t)$, at which $h\left(x_{s}\right)=0$, does not retreat.

As the incoming bore shock strength magnitude increases initially (Fig. 4(b)), so does the energy decay rate (see Fig. 4 (a)), which peaks at $x(t) \approx 7.8$. The shock strength then plateaus whereas the decay rate steadily decreases. Finally, as the shoreline is approached the shock strength increases rapidly once more, 
whilst the energy decay rate quickly $\rightarrow 0$, as the bore collapses at the shore. Therefore, we would expect maximum sediment entrainment also at $x(t) \approx 7.8$, decreasing thereafter. The energy decay rate across the backwash bore is small compared to that of the incoming bore. Its shock strength is correspondingly smaller.
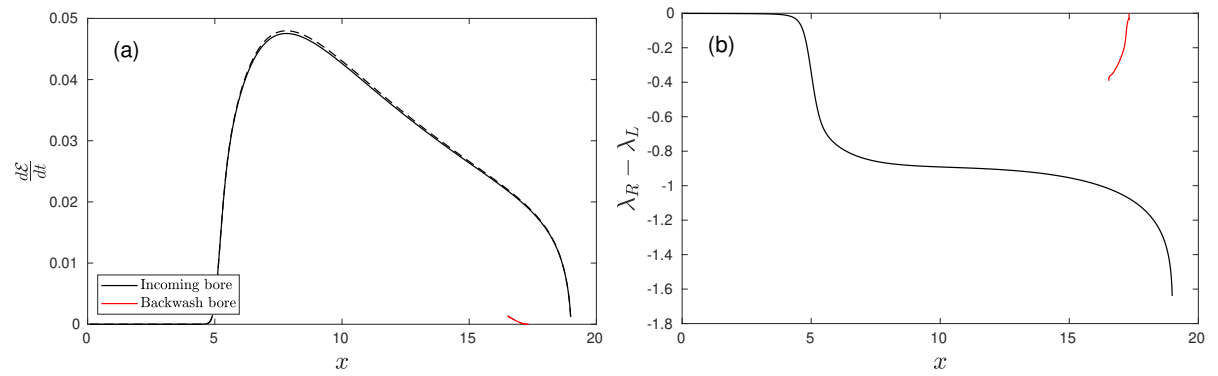

Figure 4: The energy decay rate (a) calculated from 38, and shock strength $\lambda_{R}-\lambda_{L}$ (b) across the incoming and backwash bores, as functions of $x(t)$. The dashed line in (a) shows $d \mathcal{E} / d t$ as calculated from the equivalent expression from [10.

The $h, u, B$ and $c$ differences across the incoming and backwash bores are shown in Fig. 5. Both $h_{R}-h_{L}$ and $B_{R}-B_{L}$ (Fig. $5($ a,c)) follow a trend similar to $d \mathcal{E} / d t$. In contrast, $u_{R}-u_{L}$ and $c_{R}-c_{L}$ show similarities to the shock strength, with jumps approaching a finite value as $x \rightarrow 19$ (the initial shoreline). The increasing $\left|c_{R}-c_{L}\right|$ as $x \rightarrow 19$ is because the mass flux across the shock front, $\left|m_{s}\right|=h_{L}\left|u_{L}-W\right|$, decreases as $h \rightarrow 0$ and $u_{L} \rightarrow W$ (recall that the solitary wave is propagating into still water). In other words, for a fixed $\frac{d \mathcal{E}}{d t}$, but decreased $m_{s}$, the jump in $c$ must be higher across the shock to accommodate the same volume of entrained sediment.

The sediment on the left side of the incoming shock is eroded, which results in a lower bed level in lee of the bore (i.e., as the shock propagates it leaves a lower bed level behind it); see Fig. 5(c). $c$ is higher on the left (downstream) side of the shock. This is consistent with previous analysis in $\S 2.4$.

$c$ is also higher on the downstream side of the backwash bore, and the jump in $c$ across the backwash $\left(\lambda_{3}\right)$ bore is much smaller than that across the incoming 

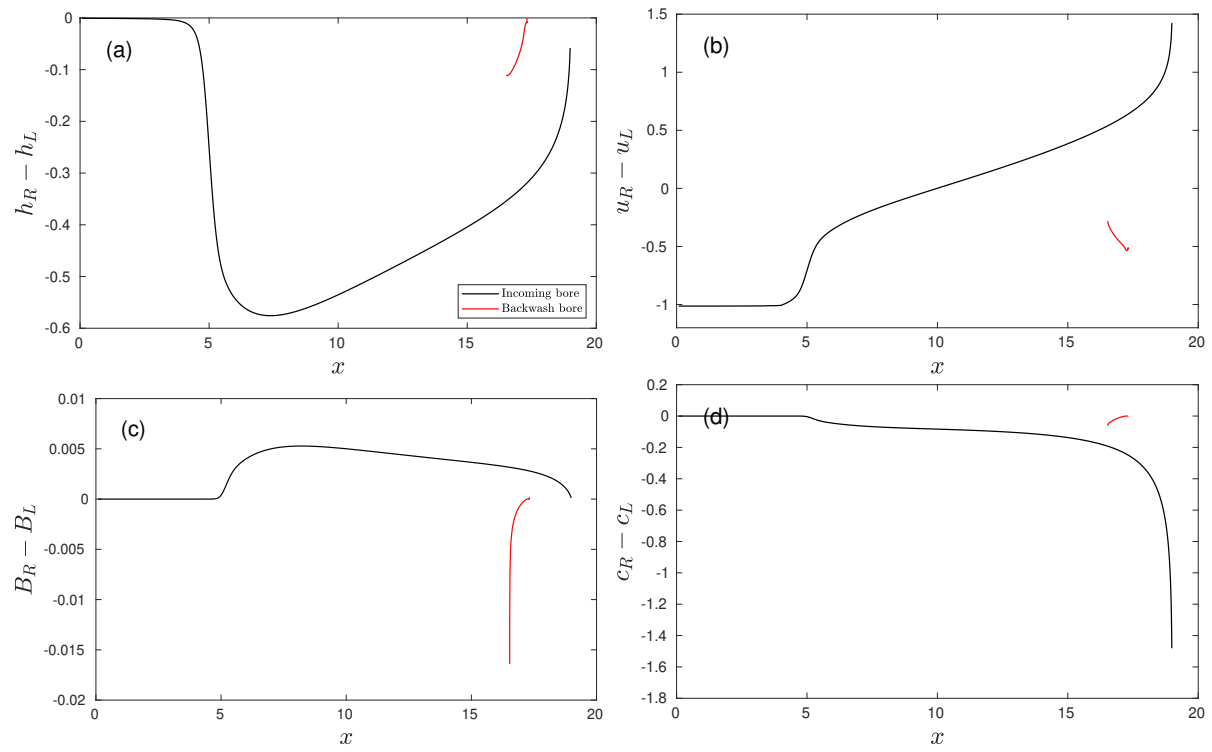

Figure 5: Water depth difference (a), velocity difference (b), bed level difference (c), and depth-averaged SSC difference (d) across the incoming bore and backwash bore as functions of $x(t)$.

bore. Jumps in $h$ and $u$ are also smaller, consistent with the smaller shock strength and decay rates.

However, the bed level difference across the backwash bore increases significantly at a later stage. This is because the backwash shock velocity $W \rightarrow 0$. In its early stages the backwash bore moves offshore, entraining sediment from upstream (shorewards here) as it does so, and therefore leaving a lower bed level in its path. As $W$ reduces, $B_{R}-B_{L}$ reduces to a large negative value, and when $W \rightarrow 0$, the bed step difference $B_{R}-B_{L} \rightarrow-\infty$ from Eq. 28).

\subsubsection{Bed change}

The bed change at a series of times for both $k=150$ and $k=300$ are shown in Fig. 6(a) (in which we normalise bed change, $\Delta B$, by $k M_{b}$ ). In the uprush, the sediment entrained by the incoming bore is partially advected into the swash zone, with that remaining seaward of the initial shoreline after the passage of 
the bore subsequently settling; see bed changes from $t=20$ to $t=56.9$ in Fig. 6(a) (remember that there is no erosion by bed shear stress here). The bed change pattern caused by the incoming bore is erosion seaward of and deposition shoreward of the initial shoreline. When $k$ is increased, the amount of erosion and deposition is proportionately increased. The pattern remains the same.
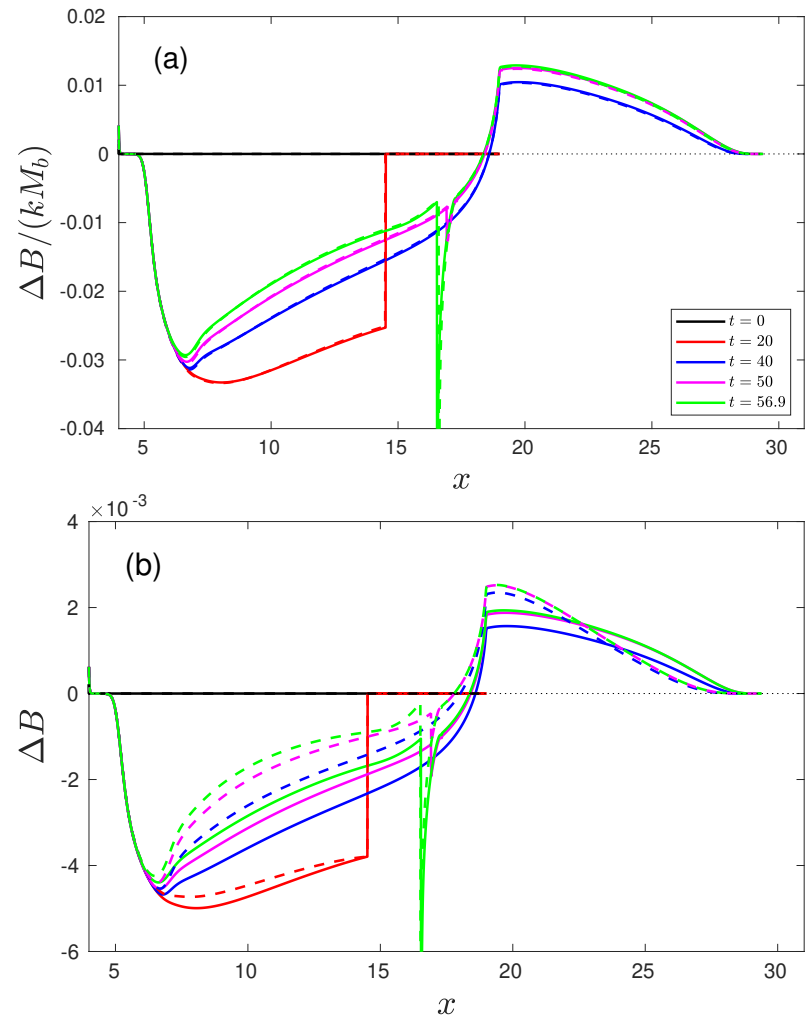

Figure 6: The bed changes, $\Delta B$, induced by sediment transport due to bore turbulence only, with (a) $k=150$ (solid lines) and $k=300$ (dashed lines), for $\epsilon=0.01$ (note that $\Delta B$ is normalised by $k M_{b}$ ); (b) $\epsilon=0.01$ (solid lines) and $\epsilon=0.02$ (dashed lines) for $k=150$.

The effect of varying $\epsilon$ (settling velocity) (Fig. 6(b)) is different. For $\epsilon=0.02$ $\left(w_{s} \approx 0.063 \mathrm{~m} / \mathrm{s}, 0.46 \mathrm{~mm}\right.$ grain size), sediment settles more quickly (note that $M_{b}$ is unchanged, so entrained sediment volume is unchanged; see incoming bore position in Fig 6(b) for $t=20$, where the solid and dashed red lines coalesce). 330 There is therefore an altered bed change pattern, with more sediment deposited 
further seaward, including in the lower swash zone.

The aforementioned limit $W \rightarrow 0 \Rightarrow B_{R}-B_{L} \rightarrow-\infty$ can be observed for the backwash bore as the sharp decrease in $\Delta B$ at $t=56.9$. Note that this bed discontinuity is opposite in sign to that usually observed in the field, and which is consistent with bed load [1]. At this point, the model breaks down, which reflects a lack of realism due to the absence of other modes of sediment mobilisation.

\subsection{Comparison of different modes of sediment mobilisation}

We now examine numerical simulations of the solitary wave event in each of which only one bed mobilisation mechanism is considered. The temporal variations of $h, u, c, h u c$ (suspended sediment transport rate) and $\frac{M}{\epsilon} \int_{0}^{t} h u c d t$ (net sediment volume passing a fixed location) are shown in Fig. 7, for simulations with suspended load entrained (solid lines) by bore turbulence only; and (dashed lines) by bed shear stress only. Locations are: $x=4$ (toe of the slope), ${ }_{345} x=10$ (about one third of the way up the slope to the initial shoreline), and $x=15$ (a little seaward of the initial shoreline). The hydrodynamics in each case are very similar (Fig. 7(a), (b)).

\subsubsection{Sediment entrainment by bore turbulence only}

At $x=4$ (Fig. 7 (c)) the wave has only just begun to form a shock (see also Fig. (4) so there is very little entrainment of sediment by bore turbulence there. In contrast, (also Fig. 7(c)) by $x=10,15$ sediment entrainment by bore turbulence is consistent with development in Fig. 5 . Comparing with observations of [3], the corresponding maximum $\rho_{s}\left(\hat{c}_{L}-\hat{c}_{R}\right)=\rho_{s}\left(c_{L}-c_{R}\right) \frac{M}{\epsilon \xi} \approx 21.8 \mathrm{kgm}^{-3}$ at $x=15$, which is consistent with some of those observed in the field.

355 The instantaneous sediment flux, huc (Fig. 7 (d)) increases instantaneously as the bore passes. And the integrated flux (Fig. 7(e)) remains clearly onshore 22, 7]. Finally, note that these time series are curtailed at $t=56.9$, when the bore turbulence model breaks down. 

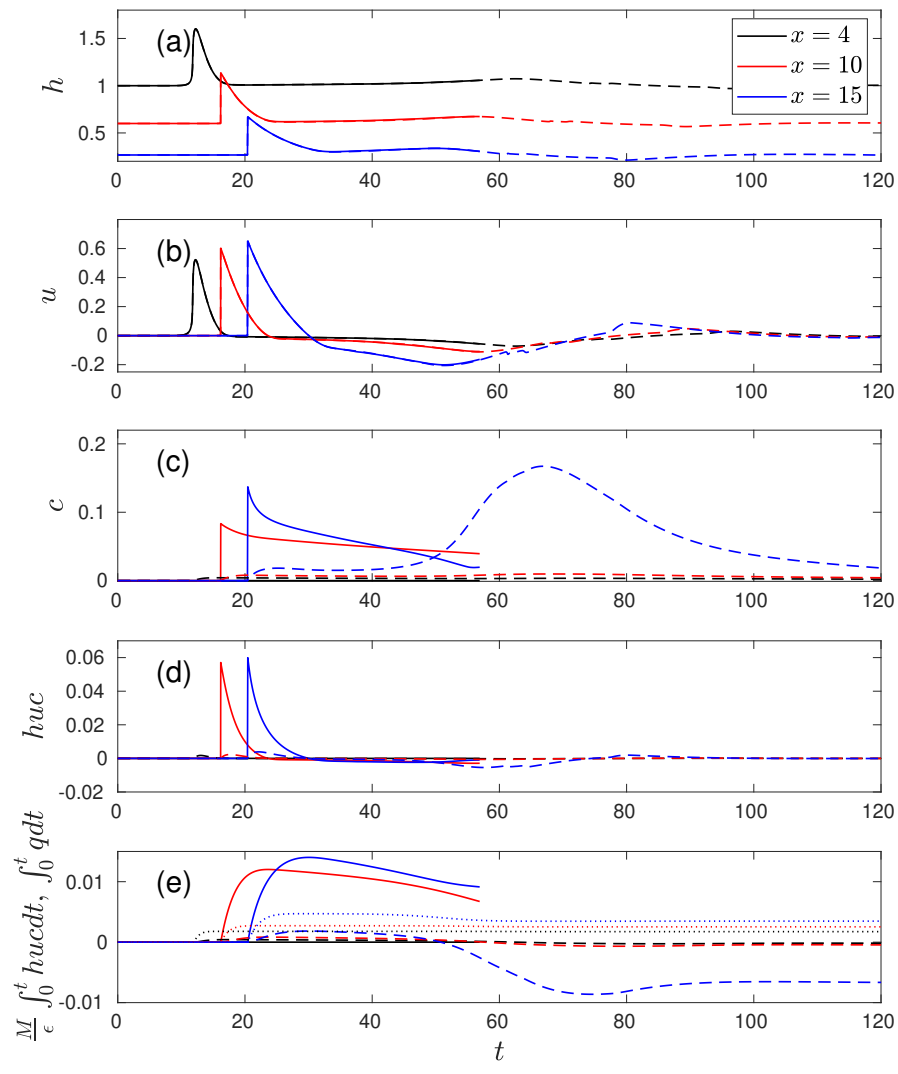

Figure 7: The temporal variations of $h, u, c, h u c$ and $\frac{M}{\epsilon} \int_{0}^{t} h u c d t$ at $x=4,10$ and 15 with $k=150$ in the simulations with suspended sediment entrained by bore turbulence only (solid lines) and bed shear stress only (dashed lines). $\int_{0}^{t} q d t$ in (e) is for bed load only case, and is indicated by dotted lines.

\subsubsection{Sediment mobilisation by bed shear stress}

360 continuous when the bore arrives (Fig. 7 (c)). The corresponding peak $c$ value is much smaller than that in the bore-turbulence-only case, although suspended sediment persists because of continuous entrainment. $c$ increases to a large value at $x=15$. This local increase is due to the advection of sediment entrained

of this: between $t=50$ and 70 , sediment is settling locally, but nonetheless 
increasing overall (this can also be viewed in Fig. 10 in $\S 4.5$ ).

The integrated flux (Fig. 7(e)) is sensitive to location in the inner surf zone, exhibiting either marginal $(x=4,10)$, or strongly net offshore $(x=15)$ flux.

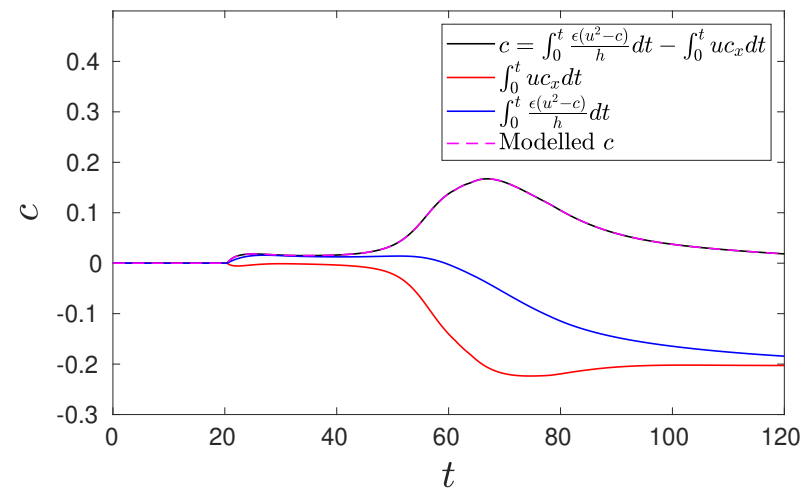

Figure 8: $\int_{0}^{t} u c_{x} d t$ (c advection) and $\int_{0}^{t} \frac{\epsilon\left(u^{2}-c\right)}{h} d t$ (net entrainment) components for the suspended only case (at $x=15)$.

The time series for suspended load caused by both bore turbulence and bed shear stress (not shown) is approximately equal to the sum of the corresponding bore-turbulence- and bed-shear-stress-only time series. In other words, over a single swash event individual entrainment processes can be viewed as additive (linear).

375 Finally, the net sediment flux due to bed load, $\int_{0}^{t} q d t$, is also shown, in Fig. 7(e). In this inner surf zone region this remains positive for the duration of the event, and is effected primarily by the passage of the incoming wave.

\subsection{Bed change comparison for individual processes}

We now consider the bed change corresponding to these simulations. The inclusion of each mechanism of sediment mobilisation yields distinctive bed changes (see Fig. 9).

\subsubsection{Bed change by bore turbulence only}

For $t=20$ and 50, $\Delta B$ displays the same pattern to that observed in Fig. 6 Sediment is eroded from the region $x<19$ (i.e. seaward of the initial shoreline), 

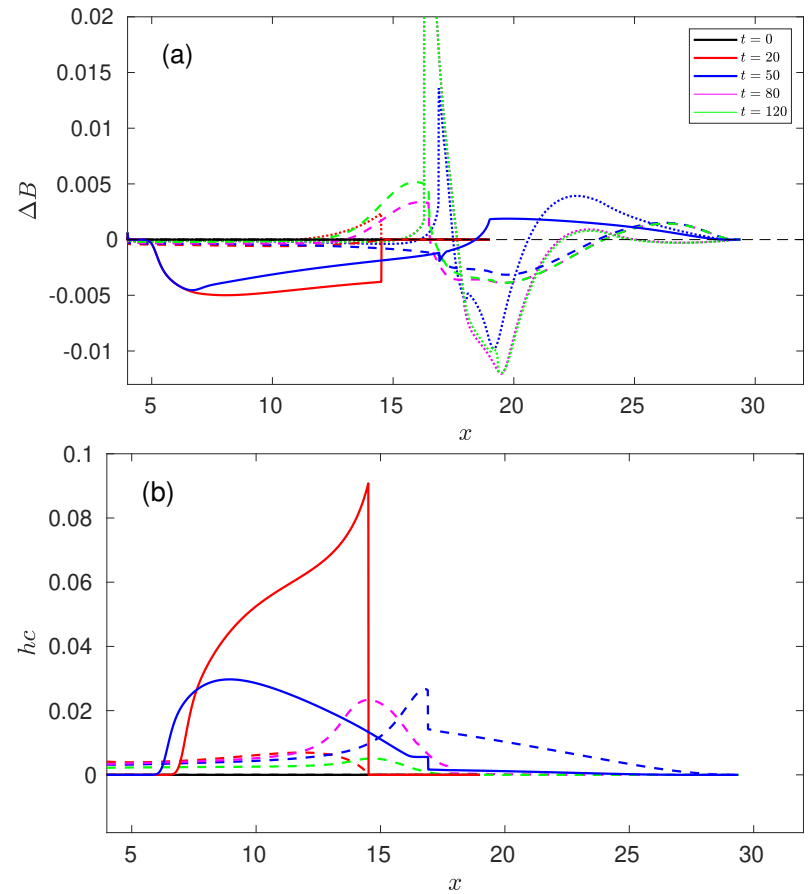

Figure 9: Comparison of snapshots of (a) bed change $(\Delta B)$ caused by sediment suspended by bore turbulence only (solid line); sediment suspended by bed friction only (dashed line); and bed load only (dotted line); (b) entrained sediment volume $(h c)$ due to bore turbulence only (solid line); bed friction only (dashed line). Times are indicated in the inset.

385 and deposited primarily just shoreward of $x=19$ (i.e. in the lower swash). In addition, (Fig. 9(b)) at $t=20$ and 50 we can see the large entrained sediment volumes, which later settle.

\subsubsection{Bed change by bed shear stress as suspended load only}

In contrast, bed friction entrains sediment before and after bore collapse.

Prior to collapse $(t=20) h c$ increases from zero at the bore front (Fig. 9(b)) because $c$ is continuous across the bore front [1]. After collapse the potential energy in the bore is translated to kinetic energy and high velocities, resulting in early dominance of erosion in the lower swash; by $t=50$ deposition has occurred in the upper swash, consistent with earlier studies [23, 1], and the 

water moves seawards leaving an increasingly thin film of water in the upper swash (Fig. $10(\mathrm{a})-(\mathrm{b}))$. One backwash $\left(\lambda_{3}\right)$ bore develops $(x \approx 17.3, t \approx 42.8)$, 
and it gradually slows and collapses at $(x \approx 16.2, t \approx 71.1)$. A weak, shoreward propagating bore also develops $(x \approx 16.3, t \approx 67.3)$ due to the convergence of $\lambda_{2}$ characteristics before the collapse of the backwash bore. The bed changes and total sediment in the water column are also shown at a series of times in Fig. 11 .
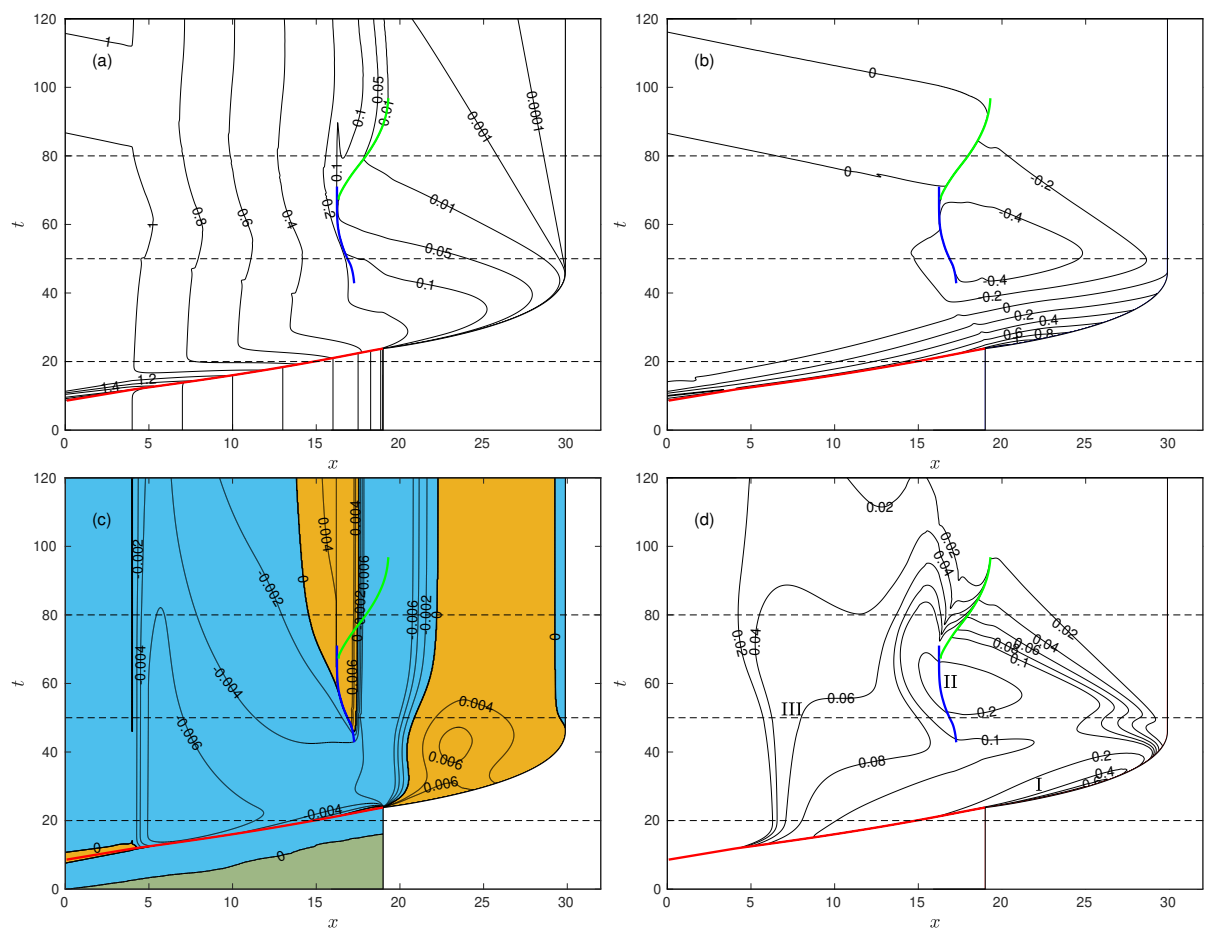

Figure 10: Comparison of contour plots during a swash event driven by a solitary wave. (a): $h$; (b) $u$; (c) $\Delta B$; and (d) $c$. In (c) brown shading indicates deposition, and blue erosion. The grey-green shading indicates still water as yet unaffected by the incoming bore, and white is the dry beach. Dashed lines indicate the times corresponding to those shown in Fig. 11 The coloured lines are the bore paths: red: incoming $\left(\lambda_{2}\right)$ bore; blue: backwash $\left(\lambda_{3}\right)$ bore; green: $\lambda_{2}$ bore.

The $c$ contour plot reflects these changes. There are three distinct local maxima readily observable in Fig. 10(d). I: a very pronounced, narrowly-confined peak close behind the uprush tip. This is due to bed shear stress, and it rapidly diminishes because of flow deceleration and the small water depth there; II: a 
region straddling the $\left(\lambda_{3}\right)$ backwash bore, primarily due to bed shear stress. Sediment initially shoreward of the shock is transported seaward and deposited; III: finally, further offshore, bore turbulence is a source of suspended sediment. This can initially be seen at the inception of breaking of the solitary wave $(x \approx 0.9, t \approx 8.6)$, and this gradually forms a lobe of sediment further offshore at later times. In addition, there is another confined local maximum in $c$ due to the weak onshore travelling $\lambda_{2}$ bore, which can be discerned in Fig. 10 (d) from the discontinuity in $c$ contours across that shock path, but is more readily observable in Fig. 11(b) $(t=80)$. This latter peak, also due to entrainment by bore turbulence, is dependent on there being no ensuing wave.
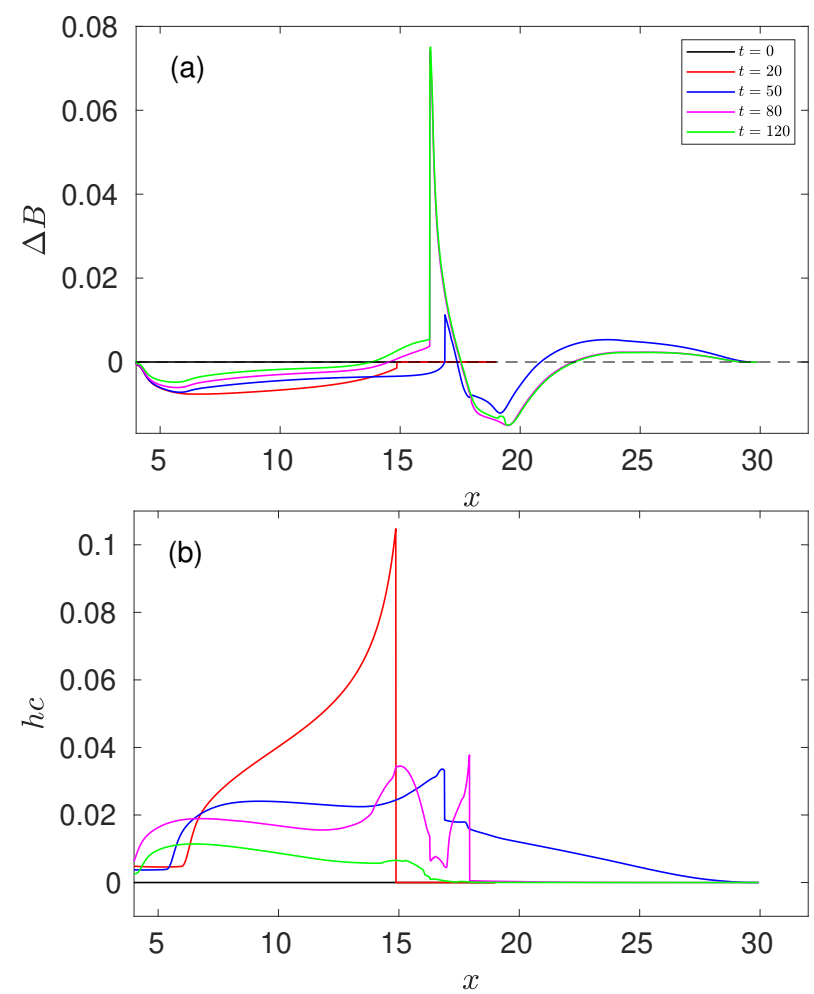

Figure 11: Snapshots for bed change $\Delta B$ and $h c$ at a series of time. (a): $\Delta B$; and (b) $h c$.

In Fig. 10.(c) we can see erosion from $4<x<19$ (inner surf zone), until $t \approx$ 43 , when the backwash bore forms, and, after which, a sub-region of deposition 
(the bed step) develops. This erosion is due to bore turbulence (see Fig. 9(a)).

In Fig. 10(c) we can also see the subsequent development of the bed step, associated with which, there are two distinct sub-regions of deposition. Shoreward of the backwash bore bed load deposition yields a very elevated bed level (due to bed load deposition). By the time that the second $\lambda_{2}$ shock has formed this region is fully developed (note the vertical contours). Seaward of the backwash bore the region remains depositional, but with an abrupt diminution in bed level. We now know that this is due to the settling out of suspended load that is entrained by bed shear stress. Note that this bed level continues to grow up to $t=120$.

The limited energy loss associated with the backwash bore, also indicates that the bed step is primarily a product of bed load via the shock relation (29) [see also 1]. Bore turbulence therefore has limited effect on the position and height of the bed step. The maximum bed change due to bore turbulence is of the order $10^{-3}$ (also see Fig. 6), which is about an order of magnitude smaller than the maximum bed change around the bed step when bed load is included. A smaller value of $\sigma$ would yield correspondingly smaller $\Delta B$ values, but, as noted by [1], the bed step height is only weakly dependent on $\sigma$.

The region straddling the initial shoreline $(x=19)$ is subject to erosion. For $x<19$ this is partly due to bore turbulence, but erosion by bed shear stress overwhelms any shoreward deposition of this sediment in the region $x>19$. This "trans $x_{s}(0)$ " region of erosion widens as the backwash builds the bed-step further offshore, in part from sediment in this region.

The overall resulting pattern of sediment redistribution (offshore to onshore) is: strong, diffuse erosion (inner surf zone; due to bore turbulence); mild, very confined deposition (just seaward of the bed-step; due to sediment entrained as suspended load by bed shear stress); very pronounced, very confined deposition (bed step; bed load); strong confined erosion (lower to mid-swash; due to mobilisation by bed shear stress, both as bed- and suspended load); mild, fairly diffuse deposition (upper swash; primarily due to bed shear stress driven 475 suspended load). 
Much of the sediment eroded by bore turbulence remains in the water column and is likely to be available for subsequent waves to advect, even when those subsequent waves are not energetic enough to entrain sediment themselves [22, 7.

In Fig. 12 we show the time variation of the volume of bore-entrained sediment that is subsequently deposited seaward or shoreward of the initial shoreline, and that which remains in the water column seaward of the initial shoreline (only a negligible amount remains in the water column for $x>x_{s}(0)$ ). By $t=50$, when the backwash is at or near its peak, a substantial amount of the bore-entrained sediment (35\%) remains in the water column, and is available to be advected by a following wave [22]. By $t=90$ (120) the swash event is over, and this percentage drops to $19 \%(12 \%)$.

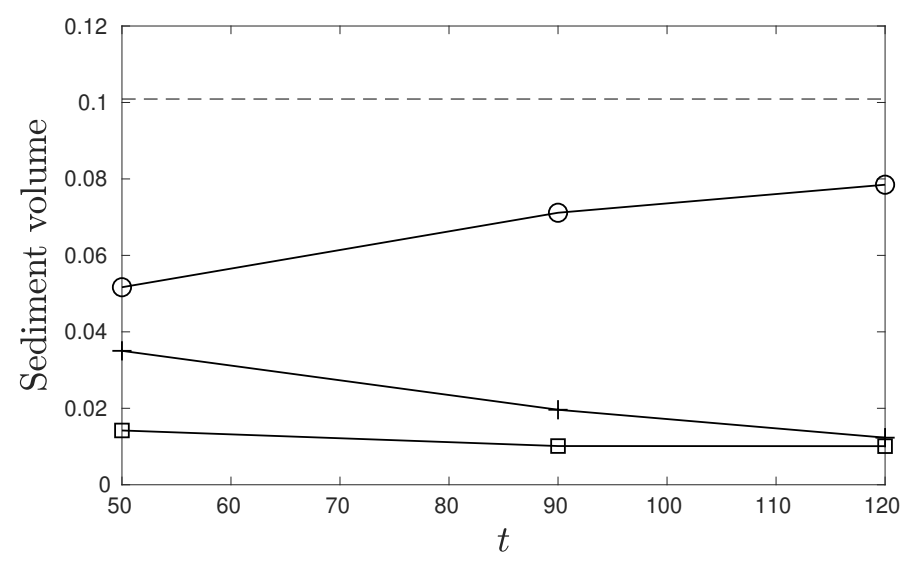

Figure 12: Sediment volume (per unit width) due to bore turbulence: $(+)$ in water column for $x<19$ (calculated by subtracting volumes with and without bore turbulence); (o) deposited in region $x<19$ after being eroded by the incoming bore; (square) deposited in region $x>19$. Times correspond to those for which the wave period is $\langle(t=50), \approx(t=90)$, and $>$ $(t=120)$ the swash period. The dashed line is the total sediment entrained by the incoming bore, calculated as $\int_{x(t=\text { bore formation }))}^{x(t=\text { bore collapse })} \frac{M_{b}}{W(x(t))} G(x(t)) d x$, from the shock relation 28 . 


\section{Discussion}

One approximation we make for the estimation of $k$ (see $\S 3.3$ ) is to equate

490

by [3]. This is clearly a crude approximation, which we use for a number of reasons. First, we employ $\hat{c}$, a depth-averaged SSC in our model. We tried experiments using a $\hat{c}$ value adjusted such that it corresponds to a true depthaveraged $\hat{c}$, as estimated from the work reported by [3. However, this resulted

This work is also limited because the bore turbulence is implicitly assumed 
to occur only at the shock, and no advection or diffusion is considered. The advection of bore turbulence has been observed in experiments [7, 25]. On a similar note, our choice of (16) also implies that maximum erosion occurs offshore of $x_{s}(0)$, at $\frac{2\left|h_{R}-h_{L}\right|}{h_{R}+h_{L}} \approx 0.56$, whereas observations indicate that that starts to occur nearer to the shoreline (albeit with a proportion of that being due to bed shear stress) at locations at which $\frac{2\left|h_{R}-h_{L}\right|}{h_{R}+h_{L}} \approx 1$ [7]. However, the shock dynamics, which we focus on, will not be affected by this, because the inclusion ${ }_{525}$ of advection of turbulence would yield another characteristic $\lambda_{5} \equiv \lambda_{4}=u$. In future modelling a combination of turbulence modelling and modification of $G$ can be considered.

\section{Conclusions}

This work has proposed a new mathematical model of bore turbulence entrainment in a NSWE morphodynamic model. The model entails use of a Dirac delta function as a source term for entrained sediment, which then yields new shock conditions. Here, sediment entrainment by bore turbulence is assumed to be proportional to the energy decay rate at the bore. The energy decay rate at a shock on a mobile bed with a bed discontinuity is derived analytically. The resulting expression asymptotes to the classical expression for a fixed bed [10, p. 291-341] (see Appendix D). The entrainment and movement of the sediment by bore turbulence via the shock relations is analysed. This approach allows an analytical estimate of energy decay rate, so that numerical back calculations are not necessary, and can be extended to incorporate an equation of generation / 540 decay / advection of turbulence intensity.

A single swash event driven by a solitary wave has been simulated, and the roles of bore turbulence, bed load and suspended load in beachface evolution are investigated. The results show that sediment entrainment by bore-generated turbulence dominates over bed shear stress related mobilisation processes for the incoming bore. We estimate that 35 to $12 \%$ of that sediment is available for advection by a subsequent wave. In contrast, sediment entrainment by bore- 
generated turbulence is much less important for the backwash bore, at which bed shear stress controls sedimentation / erosion. The bed-step, which is formed by the backwash bore, is primarily created by bed load, but suspended load to some extent counteracts this growth, by depositing sediment seaward of this feature.

\section{Appendix A. Expression for $G$ as the shoreline is approached}

Consider a bore propagating, from left to right, into still water on a nonerodible bed, on a plane beach of slope $\tan \alpha$. From [26] we know that, according

555 to shallow water theory

$$
\begin{aligned}
W & =\sqrt{\frac{h_{L}\left(h_{L}+h_{R}\right)}{2 h_{R}}} \\
u_{L} & =\left(\frac{h_{L}-h_{R}}{h_{L}}\right) W
\end{aligned}
$$

where we have used the terminology introduced in $\S 2.3$. Because the bore is propagating into still water, $h_{R}=\tan \alpha \Delta x$, and $u_{R}=0$, where $\Delta x$ is the distance from the bore to the still water shoreline. We know that $h_{L} \sim(\Delta x)^{\beta}$ as $\Delta x \rightarrow 0$, where $\beta>0$, because $h_{L}$ must $\rightarrow 0$ as $\Delta x \rightarrow 0$. For $W$ to be finite at the shoreline we must therefore have $\beta=\frac{1}{2}$, in which case $W \rightarrow u_{L}$ as $\Delta x \rightarrow 0$.

With this in mind, we note that as $\Delta x \rightarrow 0$, with $G=k \frac{d \mathcal{E}}{d t}$ and 38,26 , becomes

$$
\begin{array}{rrr}
-c_{L} & =\epsilon k\left(u_{L}\right)^{2} \frac{h_{R}-h_{L}}{2\left(h_{R}+h_{L}\right)} \\
\Rightarrow c_{L} \rightarrow & \epsilon k u_{L}^{2} \frac{1}{2}
\end{array}
$$

and therefore that $c_{L} \rightarrow$ a finite value at the shore. However, if instead

$$
G=k \frac{1}{h} \frac{d \mathcal{E}}{d t}
$$

then $c_{L} \rightarrow \infty$ as $\Delta x \rightarrow 0$, which is non-physical. 


\section{Appendix B. Non-dimensionalization of bore-turbulence only case}

In the case $M=0$, and $M_{b} \neq 0$ sediment is suspended by bore-generated turbulence only. In anticipation of this we first take $\hat{c}_{0}=\frac{\hat{m}_{b}}{\hat{w}_{s}}$, and, instead of (7), we get

$$
B_{t}+3 \xi \frac{\hat{A}}{\hat{h}_{0}\left(g \hat{h}_{0}\right)^{1 / 2}} u^{2} u_{x}=\xi \frac{\hat{m}_{b}}{\left(g \hat{h}_{0}\right)^{1 / 2}} c-\frac{\xi \hat{m}_{e}}{\left(g \hat{h}_{0}\right)^{1 / 2}} u^{2}-\xi \hat{m}_{b} \hat{\mathcal{G}}^{\prime}(\hat{x}) \delta(\hat{x}-\hat{\zeta}),
$$

570 which, for $M=0$, reduces to

$$
B_{t}+3 \sigma u^{2} u_{x}=M_{b} c-M_{b} \mathcal{G}^{\prime}(x) \delta(x-\zeta) .
$$

Similarly, instead of (8) we get

$$
(h c)_{t}+(h u c)_{x}=\frac{\xi \hat{m}_{e}}{\left(g \hat{h}_{0}\right)^{1 / 2}} u^{2}-\frac{\hat{w}_{s}}{\left(g \hat{h}_{0}\right)^{1 / 2}} c+\frac{\hat{w}_{s}}{\left(g \hat{h}_{0}\right)^{1 / 2}} \hat{k} g^{1 / 2} \hat{h}_{0}^{5 / 2} \frac{d \mathcal{E}}{d t} \delta(x-\zeta),
$$

and finally

$$
(h c)_{t}+(h u c)_{x}=-\epsilon c+\epsilon \mathcal{G}^{\prime}(x) \delta(x-\zeta) .
$$

\section{Appendix C. Hydraulic jump on a mobile bed}

In order to determine $k$ it is first useful to consider the case of a stationary shock (hydraulic jump) on a mobile bed, to see if this yields a natural expression for $k$. The logic behind this is that at such a feature bed load will deposit sediment immediately downstream, which might be balanced by entrainment, expressed through $k$. For a stationary hydraulic jump on a mobile bed, $W=0$ and $\sigma>0$, and the shock conditions become

$$
\begin{aligned}
h_{R} u_{R}-h_{L} u_{L} & =0, \quad \text { (C.1) } \\
h_{R} u_{R}^{2}+\frac{1}{2} h_{R}^{2}-h_{L} u_{L}^{2}-\frac{1}{2} h_{L}^{2}+\frac{1}{2}\left(h_{R}+h_{L}\right)\left(B_{R}-B_{L}\right) & =0, \quad(\mathrm{C} .2) \\
\sigma\left(u_{R}^{3}-u_{L}^{3}\right) & =-M_{b} G,(\mathrm{C} .3) \\
m_{s}\left(c_{R}-c_{L}\right) & =\epsilon G . \quad \text { (C.4) }
\end{aligned}
$$


If there is no entrainment due to bore turbulence, i.e., $M_{b}=0$, Eq. C.3 $\Rightarrow u_{L}=u_{R}$. In that case (C.1) and C.2 $\Rightarrow$ in general that $h_{L}=h_{R}$ and $B_{L}=B_{R}$. Thus a stationary hydraulic jump cannot exist on a mobile bed if $M_{b}=0$.

If $\sigma=0$ (no bed load), it can be seen that C.3 cannot be satisfied unless $G=0$ or $M_{b}=0$. And $G=0 \Rightarrow h_{L}=h_{R}$ (from (38) (or $u_{L}=u_{R}$, from (C.3) $\Rightarrow u_{R}=u_{L}\left(h_{R}=h_{L}\right) \Rightarrow B_{R}=B_{L}$ from (C.3). Thus, again, a stationary hydraulic jump cannot exist on a mobile bed if $\sigma=0$ and $M_{b}>0$.

For $M_{b}, \sigma>0$, C.3 and (C.4 can be satisfied such that C.3 defines $k$, so that it corresponds to the amount of entrainment by bore turbulence that exactly equals the difference in bed-load transport across the shock. Then, C.4 determines the concentration increase induced by bore turbulence, and given by (C.3). We can then see that (C.1) and (C.2) can be solved to give the usual hydraulic jump on a non-erodible bed (even though the bed is erodible). Therefore, this seems to imply the possible existence of stationary hydraulic jump on a mobile bed, which would not be possible without bore entrainment by turbulence.

Accordingly, substituting Eq. (38) into (C.3) and (C.4) gives

$$
\begin{aligned}
\sigma\left(u_{R}^{3}-u_{L}^{3}\right) & =-M_{b} k \frac{d \mathcal{E}}{d t}=-M_{b} k m_{s}\left(v_{L}-v_{R}\right)^{2} \frac{h_{R}-h_{L}}{2\left(h_{R}+h_{L}\right)}, \\
\Rightarrow k & =-\frac{\sigma\left(u_{R}^{3}-u_{L}^{3}\right)}{M_{b} d \mathcal{E} / d t} \\
m_{s}\left(c_{R}-c_{L}\right) & =\epsilon k \frac{d \mathcal{E}}{d t}=\epsilon k m_{s}\left(v_{L}-v_{R}\right)^{2} \frac{h_{R}-h_{L}}{2\left(h_{R}+h_{L}\right)} \\
\Rightarrow c_{R}-c_{L} & =k \frac{\epsilon}{m_{s}} \frac{d \mathcal{E}}{d t}
\end{aligned}
$$

However, in C.1 C.4 there are 8 unknowns: $h_{L}, u_{L}, B_{L}, c_{L}, h_{R}, u_{R}, B_{R}$ and $c_{R}$. From Eq. (C.1), we know that $u_{L}$ and $u_{R}$ have the same signs. If $u_{L}, u_{R}>0$, then $\lambda_{1 L}<0, \lambda_{2,3 L}>0, \lambda_{1 R}<0$, and $\lambda_{2,3 R}>0$. We therefore deduce that a stationary hydraulic jump cannot form because there can be no convergence of a characteristic family across the discontinuity. An analogous argument can be applied for the case $u_{L}, u_{R}<0$. Therefore, we conclude that 
we must determine $k$ by other means.

\section{Appendix D. Energy decay at a fixed bed shock with a continuous} bed

When $B_{L}=B_{R}$ and $F_{\text {bed }}=0,(34)$ becomes

$$
\begin{aligned}
\frac{d \mathcal{E}}{d t} & =\left(\frac{1}{2} h_{L}+\frac{1}{2} u_{L}^{2}\right) m_{s}-\left(\frac{1}{2} h_{R}+\frac{1}{2} u_{R}^{2}\right) m_{s}+\frac{1}{2} h_{L}^{2} u_{L}-\frac{1}{2} h_{R}^{2} u_{R} \\
& =\frac{1}{2} m_{s}\left(h_{L}-h_{R}\right)+\frac{1}{2} m_{s}\left(u_{L}+u_{R}\right)\left(v_{L}-v_{R}\right)+\frac{1}{2} h_{L}^{2} u_{L}-\frac{1}{2} h_{R}^{2} u_{R}
\end{aligned}
$$

From Eq. 21 and $B_{L}=B_{R}$,

$$
m_{s}\left(v_{L}-v_{R}\right)=\frac{1}{2} h_{R}^{2}-\frac{1}{2} h_{L}^{2}
$$

Substituting (D.2) into D.1 gives

$$
\begin{aligned}
\frac{d \mathcal{E}}{d t} & =\frac{1}{2} m_{s}\left(h_{L}-h_{R}\right)+\frac{1}{2}\left(u_{L}+u_{R}\right)\left(\frac{1}{2} h_{R}^{2}-\frac{1}{2} h_{L}^{2}\right)+\frac{1}{4} h_{L}^{2} u_{L}-\frac{1}{4} h_{R}^{2} u_{R}+\frac{1}{4} h_{L}^{2} u_{L}-\frac{1}{4} h_{R}^{2} u_{R} \\
& =\frac{1}{2} m_{s}\left(h_{L}-h_{R}\right)+\frac{1}{2}\left(u_{L}+u_{R}\right)\left(\frac{1}{2} h_{R}^{2}-\frac{1}{2} h_{L}^{2}\right)+\frac{1}{4}\left(u_{L}-u_{R}\right)\left(h_{L}^{2}+h_{R}^{2}\right)+\frac{1}{4}\left(h_{L}^{2}-h_{R}^{2}\right)\left(u_{R}+u_{L}\right) \\
& =\frac{1}{2} m_{s}\left(h_{L}-h_{R}\right)+\frac{1}{4}\left(v_{L}-v_{R}\right)\left(h_{L}^{2}+h_{R}^{2}\right) \\
& =\frac{1}{2} m_{s}\left(h_{L}-h_{R}\right)+\frac{1}{4} m_{s} h_{L}+\frac{1}{4} v_{L} h_{R}^{2}-\frac{1}{4} v_{R} h_{L}^{2}-\frac{1}{4} m_{s} h_{R} \\
& =\frac{3}{4} m_{s}\left(h_{L}-h_{R}\right)+\frac{1}{4} \frac{m_{s}}{h_{L}} h_{R}^{2}-\frac{1}{4} \frac{m_{s}}{h_{R}} h_{L}^{2} \\
& =\frac{3}{4} m_{s}\left(h_{L}-h_{R}\right)+\frac{1}{4} \frac{m_{s}\left(h_{R}^{3}-h_{L}^{3}\right)}{h_{L} h_{R}} \\
& =\frac{m_{s}\left(h_{R}-h_{L}\right)^{3}}{4 h_{L} h_{R}} .
\end{aligned}
$$

\section{Acknowledgements}

This work was supported by Natural Science Foundation of China [grant numbers 51811530012, 51509135], and the University of Nottingham. 


\section{References}

[1] F. Zhu, N. Dodd, The morphodynamics of a swash event on an erodible

beach, J. Fluid Mech. 762 (2015) 110-140. doi:https://doi.org/10. $1017 / \mathrm{jfm} .2014 .610$

[2] E. W. J. Bergsma, C. E. Blenkinsopp, K. Martins, R. Almar, L. P. Melo de Almeida, Bore collapse and wave run-up on a sandy beach, Cont. Shelf

1 Res. 174 (2019) 132-139. doi:https://doi.org/10.1016/j.csr.2019. 01.009

[3] T. Butt, P. Russell, J. Puleo, J. Miles, G. Masselink, The influence of bore turbulence on sediment transport in swash and inner surf zones, Cont. Shelf Res. 24 (2004) 757-771. doi:https://doi.org/10.1016/j.csr.2004.02. 002 .

[4] J. A. Puleo, R. A. Beach, R. A. Holman, J. A. Allen, Swash zone sediment suspension and transport and the importance of bore-generated turbulence, J. Geophys. Res. 105 (C7) (2000) 17021-17044. doi:https://doi.org/10. 1029/2000JC900024

[5] N. Kobayashi, B. D. Johnson, Sand suspension, storage, advection and settling in surf and swash zones, J. Geophys. Res. 106 (C5) (2001) 93639376. doi:https://doi.org/10.1029/2000JC000557.

[6] N. L. Jackson, G. Masselink, K. F. Nordstrom, The role of bore collapse and local shear stresses on the spatial distribution of sediment load in the uprush of an intermediate-state beach, Marine Geology 203 (2004) 109-118. doi:https://doi.org/10.1016/S0025-3227(03)00328-1.

[7] J. M. Alsina, S. Falchetti, T. E. Baldock, Measurements and modelling of the advection of suspended sediment in the swash zone by solitary waves, Coastal Eng. 56 (2009) 621-631. doi:https://doi.org/10.1016/ j.coastaleng.2009.01.007 
[8] I. Caceres, J. M. Alsina, A detailed, event-by-event analysis of suspended sediment concentration in the swash zone, Cont. Shelf Res. 41 (2012) 61-76. doi:https://doi.org/10.1016/j.csr.2012.04.004

[9] M. Brocchini, N. Dodd, Nonlinear shallow water equation modeling for coastal engineering, ASCE J. Water. Port Coast. Ocean Eng. 134 (2) (2008)

645 104-120. doi:https://doi.org/10.1061/(ASCE)0733-950X(2008)134: 2(104)

[10] J. Stoker, Water Waves, Interscience, New York, N.Y., 1957.

[11] R. Deigaard, J. Fredsøe, I. Brøker Hedegaard, Suspended sediment in the surf zone, ASCE J. Water. Port Coast. Ocean Eng. 112(1) (1986) 115-128. doi:https://doi.org/10.1061/(ASCE) 0733-950X (1986)112:1(115).

[12] N. Pujara, P. L. Liu, H. H. Yeh, An experimental study of the interaction of two successive solitary waves in the swash: A strongly interacting case and a weakly interacting case, Coastal Eng. 105 (2015) 66-74. doi:https: //doi.org/10.1016/j.coastaleng.2015.07.011

[13] R. L. Soulsby, Dynamics of Marine Sands, Thomas Telford, London, 1997.

[14] D. J. Needham, R. D. Hey, On nonlinear simple waves in alluvial river flows: a theory for sediment bores, Phil. Trans. Roy. Soc. Lond. A 334 (1991) 25-53. doi:https://doi.org/10.1098/rsta.1991.0002

[15] F. Zhu, 1d morphodynamical modelling of swash zone beachface evolution, Ph.D. thesis, Department of Civil Engineering, University of Nottingham, Nottingham, UK (September 2012).

[16] F. Zhu, N. Dodd, Riemann solution for a class of morphodynamic shallow water dam-break problems, J. Fluid Mech. 835 (2018) 1022-1047. doi: https://doi.org/10.1017/jfm.2017.794

[17] M. Brocchini, Bore-generated macrovortices on erodible beds, J. Fluid 1 Mech. 734 (2013) 486-508. doi:https://doi.org/10.1017/jfm.2013. 489. 
[18] M. Antuono, M. Brocchini, The boundary value problem for the nonlinear

1. shallow water equations, Stud. Appl. Math. 119 (2007) 73-93. doi:https: //doi.org/10.1111/j.1365-2966.2007.00378.x

[19] G. Incelli, R. Briganti, N. Dodd, Absorbing-generating seaward boundary conditions for fully-coupled hydro-morphodynamical solvers, Coastal Eng. 99 (2015) 96-108. doi:https://doi.org/10.1016/j.coastaleng.2015. 02.002

[20] M. Antuono, L. Soldini, M. Brocchini, On the role of the Chezy frictional term near the shoreline, Theor. Comput. Fluid Dyn. 26 (2012) 105-116. doi:https://doi.org/10.1007/s00162-010-0220-8.

[21] F. Zhu, N. Dodd, Net beach change in the swash: A numerical investigation, Advances in Water Resources 53 (2013) 12-22. doi:https://doi.org/10. 1016/j.advwatres.2012.10.002.

[22] T. E. Baldock, A. Kudo, P. Guard, J. Alsina, M. Barnes, Lagrangian measurements and modelling of fluid advection in the inner surf and swash zones, Coastal Eng. 55 (2008) 791-799. doi:https://doi.org/10.1016/ j.coastaleng. 2008.02 .013

[23] D. Pritchard, A. J. Hogg, On the transport of suspended sediment by a 4 swash event on a plane beach, Coastal Eng. 52 (2005) 1-23. doi:https: //doi.org/10.1016/j.coastaleng.2004.08.002

[24] D. M. Kelly, N. Dodd, Beach face evolution in the swash zone, J. n Fluid Mech. 661 (2010) 316-340. doi:https://doi.org/10.1017/ S0022112010002983.

[25] T. E. Baldock, B. Grayson, B. Torr, H. Power, Flow convergence at the tip and edges of a viscous front - experimental and analytical modelling, Coastal Eng. 88 (2014) 123-130. doi:https://doi.org/10.1016/ j.coastaleng. 2014.02 .008 
[26] H. Keller, D. A. Levine, G. B. Whitham, Motion of a bore over a sloping beach, J. Fluid Mech. 7 (2) (1960) 302-316. doi:https://doi.org/10. 1017/S002211206000150X. 